\title{
The Role of Mothers' and Fathers' Adrenocortical Reactivity in Spillover Between Interparental Conflict and Parenting Practices
}

\author{
Melissa L. Sturge-Apple and Patrick T. Davies \\ University of Rochester
}

\author{
Dante Cicchetti \\ University of Minnesota
}

\author{
E. Mark Cummings \\ University of Notre Dame
}

\begin{abstract}
Guided by the affective spillover hypothesis, the present study examined the mediational role of parental adrenocortical reactivity to interparental conflict in explaining associations between interparental conflict and subsequent changes in mothers' and fathers' parenting practices over a 2-year period in a sample of 202 parents and their 6-year-old children. Results of autoregressive path models indicated that marital withdrawal was associated with increases in adrenocortical reactivity to conflict for mothers but not fathers. Furthermore, elevated adrenocortical reactivity in turn predicted greater psychologically controlling parenting practices and inconsistent discipline over time for mothers, but was not associated with changes in maternal warmth. Implications for clinicians and therapists working with maritally distressed parents and families are discussed.
\end{abstract}

Keywords: interparental conflict, parenting, physiology, parent-child relations

Research has shown that living in intact homes characterized by high-conflict and disharmonious interparental relationships has substantial negative implications, including increased risk for depression (e.g., Beach \& Fincham, 1998), poorer physical health outcomes for husbands and wives (e.g., Burman \& Margolin, 1992; Kiecolt-Glaser \& Newton, 2001), poorer child adjustment (e.g., Sturge-Apple, Davies, \& Cummings, 2006), and problematic parent-child relationships (e.g., Owen \& Cox, 1997). The accumulation of the findings in the literature on the detrimental impact of poor marital relationships across family systems makes it abundantly clear the empirical and clinical importance of identifying and delineating the processes by which perturbations within the marital relationship has a detrimental

Melissa L. Sturge-Apple and Patrick T. Davies, Department of Clinical and Social Sciences in Psychology, University of Rochester; Dante Cicchetti, Institute of Child Development, University of Minnesota; E. Mark Cummings, Department of Psychology, University of Notre Dame.

This research was supported by National Institute of Mental Health Grant R01 MH57318 to Patrick T. Davies and E. Mark Cummings and Grant R21 NR010857-01 to Melissa L. SturgeApple. We thank the children, parents, teachers, and school administrators who participated in this project. We also thank the staff on the project, including: Courtney Forbes, Courtney Henry, Marcie Goeke-Morey, Amy Keller, Michelle Sutton, and the graduate and undergraduate students at the Universities of Rochester and Notre Dame. We also thank Doug Granger for his valuable advice in the analysis of the cortisol data.

Correspondence should be addressed to Melissa Sturge-Apple, Mt. Hope Family Center, University of Rochester, Rochester, NY 14627. E-mail: Melissa_sturge-apple@urmc.rochester.edu impact upon other family systems (e.g., Davies \& Cicchetti, 2004; Grych, 2002).

To account for this association, theoretically driven process models of interparental discord have focused on understanding how affect and emotion arising from interparental conflict "spills over" or sets in motion processes that ultimately influence interactions within the parent-child system and may ultimately impact children's adjustment (Easterbrooks \& Emde, 1988; Grych, 2001). However, these directions in research have yet to identify the specific underlying mechanisms that can account for the transfer of emotions from one family subsystem into another. The paucity of process-oriented research on emotional transfer between interparental and parent-child subsystems is made more problematic in light of the disproportionate number of homes characterized by interparental hostility and aggression (i.e., National Survey of Children's Health, 2003) and the clinical value of identifying the etiology of parenting difficulties (Emery, Fincham, \& Cummings, 1992).

Physiological reactivity associated with emotional arousal during interparental conflict may operate as one possible mechanism contributing to links between interparental conflict and subsequent parenting difficulties. Conceptual frameworks in the broader literature on family risk suggest that physiological functioning in the context of interparental difficulties may serve as an important explanatory mechanism in developmental process models (e.g., Repetti, Taylor, \& Seeman, 2002). Several studies support the notion that difficulties and conflict in marital relationships have significant implications for an individual's physiological reactivity (e.g., Gottman \& Levenson, 1988; Kiecolt-Glaser \& Newton, 2001). For example, research 
conducted by Kiecolt-Glaser, Glaser, Cacioppo, and Malarkey (1998) examined neuroendocrine responses to marital conflict and reported that negative behaviors during marital conflict accounted for $24 \%$ of the variance in changes in neuroendocrine levels. However, despite the potential value of understanding how physiological reactivity to interparental conflict may operate in the broader family context (e.g., Kiecolt-Glaser \& Newton, 2001), no study to our knowledge has extended this work to test explanatory models of affective spillover between interparental conflict and parenting difficulties. Therefore, in response to this gap, the present study examines a longitudinal, process-oriented account of physiological reactivity to conflict and how it may serve as a mediating mechanism by which interparental conflict increases parenting difficulties in mothers and fathers over time. In addition, guided by conceptualizations demarcating the importance of differentiating types of interparental conflict in family process models (e.g., Katz \& Gottman, 1996; Sturge-Apple et al., 2006), the present study will also delineate how interparental hostility and withdrawal may exert a differential impact upon parent's physiological arousal and in turn undermine parenting practices over time.

To address the paucity of research on physiological reactivity in explanatory models of affective spillover, we specifically examine associations with parent's limbichypothalamic-pituitary-adrenocortical (LHPA) system reactivity to interparental conflict and parenting difficulties. The LHPA axis is intimately linked to the psychobiology of the stress response, with the short-term adaptive function of marshalling psychophysiological resources in the presence of emotionally significant events (Cahill \& McGaugh, 1998; Gunnar \& Vazquez, 2006). In response to stressful events, components of the limbic system (e.g., amygdala, hippocampus) involved in processing aversive stimuli modulate the release of corticotropin-releasing hormone (CRH), which in turn activates the adrenal gland to secrete cortisol by stimulating the pituitary gland to produce and release adrenocorticotropic hormone (ACTH) into the bloodstream (Chrousos \& Gold, 1992; McEwen \& Stellar, 1993). Increases in cortisol in response to stress mobilize energy (e.g., glucose, oxygen), increase cardiovascular activity, and modulate the processing of emotionally significant events.

Notions of affective spillover regarding marital conflict and parenting offer little guidance with regard to the interplay between interparental conflict, adrenocortical reactivity to conflict, and parenting difficulties. However, conceptualization of the physiological underpinnings of individual psychological functioning in reactions to a potential stressor drawn from literature on threat and challenge situations (see Lopez, Vazquez, \& Olson, 2004) may help shape predictions as to the nature and magnitude of cortisol reactivity as an explanatory mechanism in affective spillover models. According to the hypercortisolism hypothesis (e.g., Repetti et al., 2002), chronic exposure to stressful contexts that exceed coping capacities is posited to be linked with maladaptive elevated LHPA activity. By extension, the taxing nature of interparental discord may engender amplified cortisol reactivity and, ultimately, trigger a physiological cas- cade leading to greater reactivity and difficulties in engaging in optimal parenting when parents are faced with demanding and taxing childrearing interactions. It follows that amplified cortisol reactivity in response to repeated experiences with interparental conflict may be associated with greater perturbations in parenting over time, particularly within parenting domains associated with disciplinary and control issues.

Although no study has examined the interplay between parent's physiological regulation in the context of stressful interparental interactions and subsequent parenting difficulties, recent research examining parental physiological arousal within the parent-child context and associated linkages with perturbations in parenting provides some empirical support for expecting elevated physiological reactivity to operate as a potential underlying mechanism in spillover from interparental conflict. In a study of concurrent associations between physiological reactivity and parenting, Lorber and O'Leary (2005) reported that stressful parenting interactions with children predicted increases in autonomic nervous system reactivity, which in turn was associated with greater use of overreactive discipline in a sample of mothers and young children. Martorell and Bugental (2006) reported that elevated maternal cortisol reactivity stemming from her involvement in a stressful parenting context (e.g., the Strange Situation paradigm) was associated with higher use of harsh parenting practices in child discipline situations.

These studies thus support to the application of the hypercortisolism hypothesis within the family context and suggest that parental physiological reactivity may be strongly associated with increased capacity for punitive and harsh parenting. Furthermore, cognizant of the need to examine physiological correlates across multiple parenting practices, three primary dimensions of childrearing practices are assessed: parental warmth, parental psychological control, and parental inconsistent discipline (Baumrind, 1971; Steinberg, Elmen, \& Mounts, 1989). Each of these parenting practices has been associated with interparental difficulties (e.g., Sturge-Apple et al., 2006).

This study examined these relations in a sample of families with kindergarten children. Self-confidence, peer relations, cooperation, and school adaptation are stage-salient issues for school-aged children that challenge parents to reorganize childrearing practices in a way that promotes open communication, acceptance, and new forms of monitoring and discipline (Cummings, Davies, \& Campbell, 2000). Thus, the need for plasticity in parenting roles may amplify the impact physiological arousal in the context of interparental discord during this developmental period.

In sum, this study expands tests of the affective spillover hypothesis by delineating the mediational role of parent adrenocortical reactivity to interparental conflict in pathways between interparental withdrawal and hostility with parental warmth, inconsistent discipline, and psychological control in school-aged children. In accordance with genderdifferentiated hypotheses of physiological underpinnings in linkages between interparental discord and parenting (e.g., Gottman \& Levenson, 1988; Kiecolt-Glaser et al., 1996), we specified models comparing mothers' and fathers' cor- 
tisol reactivity and hypothesized that linkages would be positive and stronger for women compared with men. Furthermore, given the convergence of findings in the scant literature on physiological reactivity and parenting practices, we hypothesized that parental physiological dysregulation in the wake of interparental conflict would be more strongly related to parenting involving control and discipline in comparison to parental warmth. To provide a rigorous test of the applicability of path models, we employed a multimethod measurement battery spanning observational assessments, physiological assessments, and self-report assessments and conducted prospective analyses through the use of autoregressive models to examine associations with subsequent parenting difficulties at Time 2 (i.e., 2 years later) after controlling for Time 1 parenting difficulties.

\section{Method}

\section{Participants}

The data for this study were drawn from a larger project focusing on linkages between family processes and child coping and psychological adjustment. The original sample of 236 kindergarten children and their families in the first wave of the study were recruited through local school districts and community centers in a moderate-sized metropolitan area in the Northeast and a small city in the Midwest. Because of differences in the start dates of the larger project and the supplemental study of cortisol reactivity, cortisol measures were obtained for 204 of the 236 parent dyads. The retention rate for this sample from the first to final measurement occasion was $90 \%$, resulting in a sample of 182 families. Minimal differences were found between the retained sample and those participants lost to attrition over the two waves $(n=22)$. Therefore, in order to maximize study power, we elected to retain the full sample for study analyses and utilized full-information likelihood when estimating missing data within model analyses. Finally, two families were identified as multivariate outliers across all models specified in this study and were therefore excluded from the analyses. Thus, the final sample for this study consisted of 202 families.

A primary goal of our recruitment strategies was to obtain a demographically representative sample of families who, on the whole, exhibited diverse levels of interparental adversity. Consistent with this goal, families were socioeconomically and demographically representative of the counties from which they were drawn. Median family income of the participants fell between $\$ 40,000$ and $\$ 54,000$, with $12 \%$ of the sample reporting household income below $\$ 23,000$. A large proportion of the sample was European American (78.6\%), followed by smaller percentages of African American (15.2\%), Latin American (3.1\%), Asian American (1.2\%), Native American (0.2\%), and other racial (1.7\%) families. Families in the study also experienced diversity of interparental adversity in the family as $53 \%$ of the couples containing at least one maritally dissatisfied partner based on scores below 100 on the Short Marital Adjustment Test (Locke \& Wallace, 1959).

\section{Procedures}

Data for this longitudinal study were collected at two measurement occasions spaced two years apart. At each wave, families visited the laboratories twice within a 1 -week period at one of the research sites. The laboratories were designed to be comparable in size and quality and included: (a) an observation room that was designed to resemble a family room (e.g., couch, pictures, lamps, end tables) and equipped with audiovisual equipment to capture family interactions, and (b) interview rooms for completing confidential survey measures.

Interparental interaction task. At the first visit of Wave 1, mothers and fathers participated in a marital interaction task in which they discussed two common, intense interparental disagreements that they viewed as problematic in their relationship. Following similar procedures in previous research (e.g., Du Rocher Schudlich, Papp, \& Cummings, 2004), each parent was asked to independently select the top three most problematic topics of disagreement in their relationship they felt comfortable discussing. After this procedure, partners conferred to select one topic from each of their lists that they both felt comfortable discussing and subsequently discussed each topic for $10 \mathrm{~min}$. Videotaped records of the interactions were coded later for interparental conflict behaviors. Consistent with the use of similar interaction tasks in prior research, the aim of the interparental interaction task was to assess parents' characteristic ways of managing conflict in the interparental relationship (Du Rocher Schudlich et al., 2004). To examine the validity of this assumption, mothers and fathers completed a postinteraction interview in which they individually responded to the question, "Overall, how much did the discussion resemble disagreements that usually occur between you and your partner at home?" Response alternatives included: (1) a lot more negative, (2) somewhat more negative, (3) a little more negative, (4) about the same, (5) a little more positive, (6) somewhat more positive, and (7) a lot more positive. Supporting the comparability of the interactions to conflicts that occur in the home, the means of mother and father responses fell between "about the same" and "a little more positive" on the 7-point scale $(M=4.76, S D=.90$ and $M=$ $4.75, S D=1.08$, respectively) supporting the assumption that the conflict procedures reflected parents' typical methods of managing conflict in the home.

Salivary cortisol collection. Saliva samples were collected from mothers and fathers at two points during the interparental interaction procedure to obtain cortisol measures. Diurnal rhythms of cortisol reflect higher declines observed in early morning, with more gradual declines during the afternoon and evening hours (Stansbury \& Gunnar, 1994). Thus, to limit the effects of the strong diurnal decline present in the morning on assessing reactivity, sample collection times for cortisol were all collected in the afternoon or early evening. Average sampling time for pre-task cortisol occurred at 4:31 p.m. ( $S D=2 \mathrm{hr}, 11 \mathrm{~min}$; range $=12: 30$ p.m. to 7:38 p.m.). The pretask sample was collected prior to the first discussion and the postconflict saliva sample was obtained $25 \mathrm{~min}$ after the marital inter- 
action. Although wide variability is evident across studies in the temporal spacing of poststressor cortisol measures (Fox, Hane, \& Perez-Edgar, 2006), our selection of the timing was based on meta-analytic findings indicating that peak cortisol levels across 10-min periods following the stressor were highest during the 21- to 30-min epoch than any other 10-min period (Dickerson \& Kemeny, 2004). Following conventional sampling procedures (Schwartz, Granger, Susman, Gunnar, \& Laird, 1998), parents rinsed their mouths with water prior to the baseline assessment to limit the undue influence of various contaminants during the assay process. For each cortisol assessment, parents chewed Trident original flavor sugarless gum to stimulate saliva flow immediately prior to saliva collection. Parents then expurgated through a plastic straw directly into a $20-\mathrm{mL}$ collection vial. Saliva samples were immediately stored at -36 ${ }^{\circ} \mathrm{C}$ until shipped on dry ice to Salimetrics LLC (State College, PA). Finally, mothers and fathers independently completed survey assessments of parenting practices at Times 1 and 2.

\section{Measures}

Interparental Conflict. Maternal and paternal behaviors during the interparental discussion tasks during the Wave 1 visit were evaluated using subscales from the System for Coding Interactions in Dyads (SCID; Malik \& Lindahl, 1996). The SCID yielded molar ratings of affective and communicative behaviors of husbands and wives for each of the two marital interactions on 5-point continuous scales ranging from (1) very low to (5) high. The rating scale has been widely used across different populations and has demonstrated validity in its relation to similar measures of marital interaction and reliability across studies (Malik \& Lindahl, 1996).

Maternal and paternal hostility during each of the marital interactions were assessed using the Negativity and Conflict scale which reflects spousal displays of anger, frustration, and tension. Intraclass correlation coefficients, which indexed the reliability of two independent coders for $25 \%$ of the interactions, ranged from .85 to .98 for mothers and fathers across each of the interactions. Given the high correlation between the scales across the two discussion tasks for mothers and fathers ( $r$ s between .40 and .78 ), the four codes were aggregated to yield a more parsimonious composite of interparental hostility.

Consistent with the marital hostility measurement battery, mothers' and fathers' withdrawal during the marital interactions was assessed using the Withdrawal scale from the SCID (Malik \& Lindahl, 1996), with higher scores reflecting displays of repeated, prolonged, and intense forms of detachment and avoidance during the marital interactions. Intraclass correlation coefficients, which index interrater reliability, ranged from .85 to .96 for mothers and fathers across each of the two interactions. In light of significant intercorrelations for each code over the two interactions $(r=.49$ to .52$)$, ratings of withdrawal for mothers and fathers across the two interactions were aggregated to form a single measure of interparental withdrawal.
Cortisol. All samples were assayed for salivary cortisol at Salimetrics, Inc. in duplicate using a highly-sensitive enzyme immunoassay. The test used 25 ul of saliva per determination has a lower limit of sensitivity of $0.003 \mathrm{ug} / \mathrm{dl}$, standard curve range of from 0.007 to $1.8 \mathrm{ug} / \mathrm{dl}$, and average intra- and interassay coefficients of variation $5.1 \%$ and $8.2 \%$, respectively. Method accuracy, determine by spike recovery, and linearity, determined by serial dilution are $103 \%$ and $96 \%$. Values from matched serum and saliva samples show the expected strong linear relationship, $r(63)=0.89, p<.0001$ (Salimetrics, 2000).

Parental acceptance. Mother's and father's self reports on the 20-item Acceptance Scale of the Parental Acceptance and Rejection Questionnaire (PARQ; Rohner, 1990) were used to assess parental acceptance. Items were rated on 5-point Likert scales ranging from $1=$ "never" to $5=$ "always" (e.g., "You make your child feel wanted or needed"). The psychometric properties of the PARQ Acceptance Scale are well established (e.g., Rohner, 1990). Internal consistency coefficients for mothers and fathers at Time 1 and Time 2 were satisfactory ( $\alpha$ s ranged from .88 to .93 ).

Inconsistent discipline. Mother's and father's reports of their inconsistency in discipline with their child were measured using the Inconsistent Discipline scale from the Alabama Parenting Questionnaire (APQ; Shelton, Frick, \& Wootton, 1996). The six items on the Inconsistent Discipline scale (e.g., "You threaten to punish your child and then do not actually punish him/her.") are rated by parents along response scales ranging from 1 (never) to 5 (always). The validity and reliability of the Inconsistent Discipline scale is supported by previous research (e.g., Shelton et al., 1996). Internal consistency coefficients for mothers and fathers at Time 1 and Time 2 were satisfactory ( $\alpha$ s ranged from .73 to .78 ).

Psychological control. Mother's and father's reports of their own use of psychologically controlling parenting behaviors with their child were measured using the Control Through Guilt, Instilling Persistent Anxiety, and Intrusive Subscales from the Child Report of Parenting Behaviors Inventory (CRPBI; Margolies \& Weintraub, 1977; Schludermann \& Schludermann, 1970). Items on each of the subscales were rated on 5-point Likert scales ranging from 1 (never) to 5 (always). The Control Through Guilt subscale contains five items designed to assess parental psychological control strategies that induce guilt (e.g., "You let your child know you feel hurt by the things he/she does"). The Instilling Persistent Anxiety subscale is comprised of five items indexing psychological control strategies that are likely to evoke considerable worry on the child's part (e.g., "You think that any misbehavior is serious and will have future consequences"). The Intrusive subscale consists of five items measuring parents' over-involvement in children's daily activities (e.g., "You keep a careful check on your child to make sure s/he has the right kind of friends."). The subscales each have been shown to possess satisfactory internal consistency and previous research has supported the convergent and discriminant validity of the measures (Schwarz, Barton-Henry, \& Pruzinsky, 1985). Intercorrela- 
tions among the three subscales ranged from moderate to strong in magnitude for mothers and fathers at each measurement occasion ( $r$ s range from .31 to .67). Thus, the three subscales were summed to form composites for mother ( $\alpha \mathrm{s}=.84$ and .81 for the combined subscales at Waves 1 and 2 , respectively) and father $(\alpha s=.85$ and .83 for the combined subscales at Waves 1 and 2, respectively) psychological control.

\section{Results}

\section{Cortisol Reactivity}

To create manifest variables of mother's and fathers' cortisol reactivity to the interparental disagreement task, we followed a standard procedure used in previous studies which utilizes residualized gain scores to index reactivity (e.g., Granger, Weisz, \& Kauneckis, 1994; Granger, Weisz, McCracken, Ikeda, \& Douglas, 1996). This strategy employs linear regression to control for the effects of intital (baseline) cortisol levels and sample collection time (e.g., time of day) on individual differences in cortisol reactivity. In the first step, postconflict scores were predicted from corresponding baseline cortisol scores and sample collection time using linear regression. In the second step, residualized post conflict scores were computed by subtracting the predicted score from the observed post conflict score. Higher residualized gain scores reflect larger task-related increases in salivary cortisol from baseline to postconflict after controlling for time of day. Residual post conflict scores, which indexed cortisol reactivity to the interparental exchange, were used in the primary analyses. After transformations, data were checked for possible outliers. Three cases had reactivity values that were greater than 3.5 standard deviations away from the mean. In order to retain these cases, winsorizing was utilized in which the highest value on the distribution was substituted for the outlier case.

\section{Primary Analyses}

For descriptive purposes, means, SDs, and intercorrelations among interparental discord and parenting variables are provided for boys and girls in Table 1 .

To examine our spillover process model, we employed a path analysis within a Structural Equation Modeling (SEM) framework (e.g., Kline, 2006). Path analysis provides for the testing of relationships among multiple manifest variables within longitudinal process models, allows for simultaneous assessment of multiple outcome variables, and produces evidence of model fit and misspecification. In the present study, path models were estimated using the fullinformation maximum likelihood method (FIML) through the AMOS 7.0 statistical software (Arbuckle \& Wothke, 1999), which allows for the estimation of missing data within the original variance/covariance matrix. FIML is more sophisticated when compared with other well-known methods such as replacement with the mean in that it strives to maintain the integrity of the data variance-covariance matrix. Finally, the fit of our path models was assessed using the (a) the root mean square error of approximation (RMSEA), with values of .08 or less reflecting reasonable fit (Browne \& Cudeck, 1993) and (b) the comparative fit index (CFI) statistic with values between .95 and 1.00 indicating acceptable fit (Bentler, 1990).

Given the potential moderating role of child gender in models of family process (Davies \& Lindsay, 2001), we initially examined whether the proposed links between interparental conflict, cortisol reactivity, and parenting differed as a function of child gender by splitting the data by boys and girls and estimating models simultaneously using a multiple-group analysis (for details on this approach, see Sturge-Apple et al., 2004). First, we examined the multiple group model with paths between each interparental conflict variable, cortisol and each specific parenting variable at Wave 2 constrained to be equal across child gender. This model fit the data well, $\chi^{2}(75, N=202)=115.70, p=$ .001$, RMSEA $=.04$, CFI $=.95)$. Next, we estimated a model in which parameters were allowed to freely vary. This model fit the data well, $\chi^{2}(70, N=202)=113.42, p=$ .001$, RMSEA $=.04$, CFI $=.95)$. Comparisons of the fully constrained and the child gender model revealed no difference in fit, $\Delta \chi^{2}(5, N=202)=2.28, p<.05$, thus indicating that child gender did not moderate the proposed links. Therefore, all subsequent analyses were performed with the full sample.

\section{Process Model Analyses}

In the first step, we sought to determine whether interrelations between forms of interparental conflict and parenting difficulties supported tests of cortisol reactivity as a mediating or intervening mechanism. A path model analysis provided an acceptable fit to the data, $\chi^{2}(25, N=202)=$ $56.2, \mathrm{CFI}=.95$, and $\mathrm{RMSEA}=.05$. In examining relations with mother's parenting practices over time, interparental withdrawal at Time 1 was a significant predictor of increases in maternal psychological control and inconsistent discipline from Time 1 to Time $2(\beta s=.17$ and $.15, p<$ .01 , respectively) whereas interparental hostility predicted increases in maternal acceptance over time, $\beta=.21, p<$ .01. Interparental hostility and withdrawal were differentially associated with mother's cortisol reactivity to the interparental conflict. Specifically, only interparental withdrawal had a significant and positive impact on cortisol reactivity, $\beta=.21, p<.01$.

For the fathers, neither interparental withdrawal nor hostility at Wave 1 were associated with changes in fathers' parenting over, or with their cortisol reactivity to conflict. Given differential findings for mothers and fathers with respect to the impact of withdrawal on cortisol reactivity, we examined if these paths were significantly different from one another. Path comparisons revealed non-significant differences between interparental withdrawal and cortisol reactivity for mothers and fathers, suggesting that while interparental withdrawal had a significant impact on mother's cortisol reactivity this effect was not statistically different from fathers $(z=1.16, p>.05)$. 


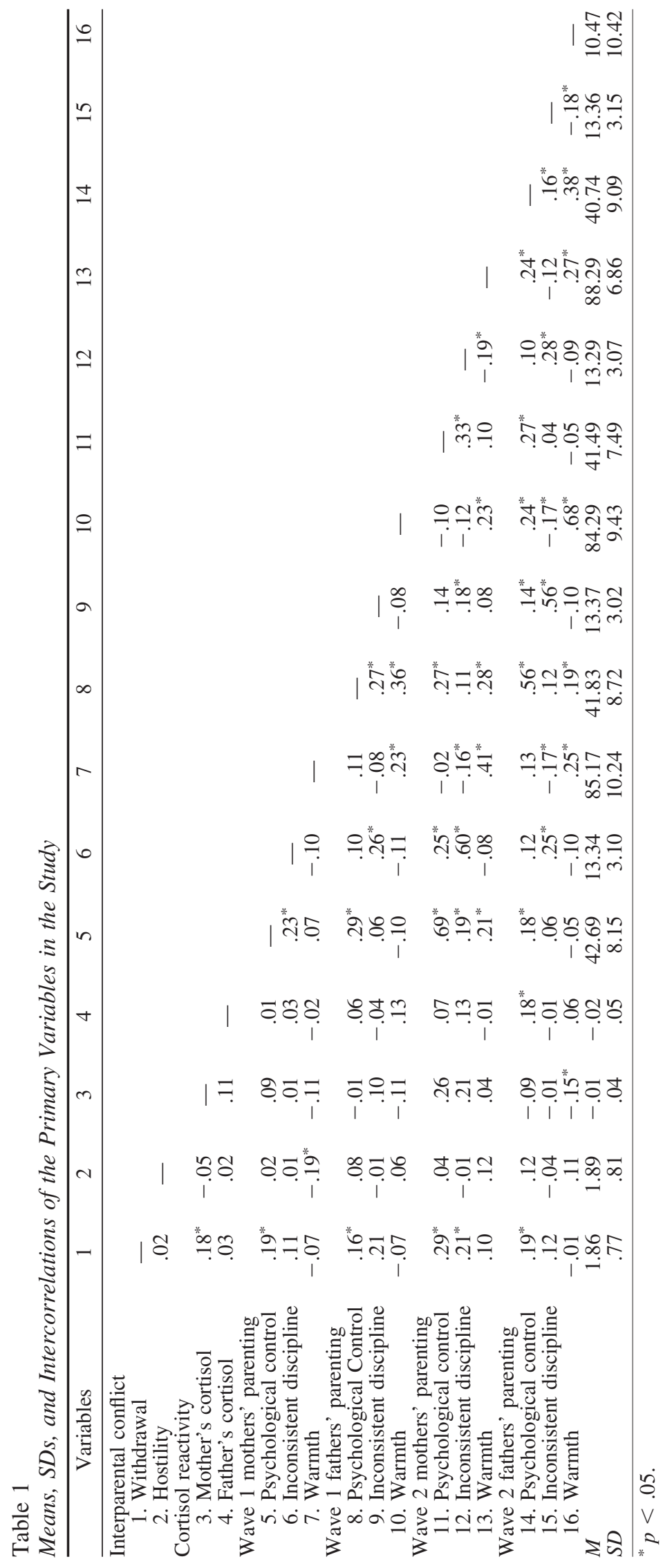


Given the presence of significant direct effects for mothers, we next investigated whether mother's cortisol reactivity to conflict mediated the direct effects of interparental withdrawal at Time 1 on changes in maternal parenting practices from Time 1 to Time 2. To accomplish this, we specified paths between maternal cortisol reactivity to interparental conflict at Time 1 and maternal warmth, inconsistent discipline and psychological control at Time 2. Our mediating model is presented in Figure 1; for ease of interpretation only significant pathways are included. The model fit the data well, $\chi^{2}(19, N=202)=27.24, p=.07, \mathrm{CFI}=$ .99 , and RMSEA $=.03$. First, path coefficients revealed that maternal cortisol reactivity to interparental conflict at Time 1 was a potent predictor of increases in maternal psychological control and inconsistent discipline from Time 1 to Time 2 ( $\beta s=.16$ and $.19, p<.01$, respectively), but did not predict changes in maternal warmth from Time 1 to Time 2 $(\beta=.08, p=.24)$. Because maternal cortisol reactivity was a significant predictor of maternal psychological control and inconsistent discipline, we were able to explore the mediational impact that it had on the direct effect of interparental withdrawal. Examination of the direct path coefficient revealed that the effect of interparental withdrawal on maternal inconsistent discipline had been reduced to nonsignifi-
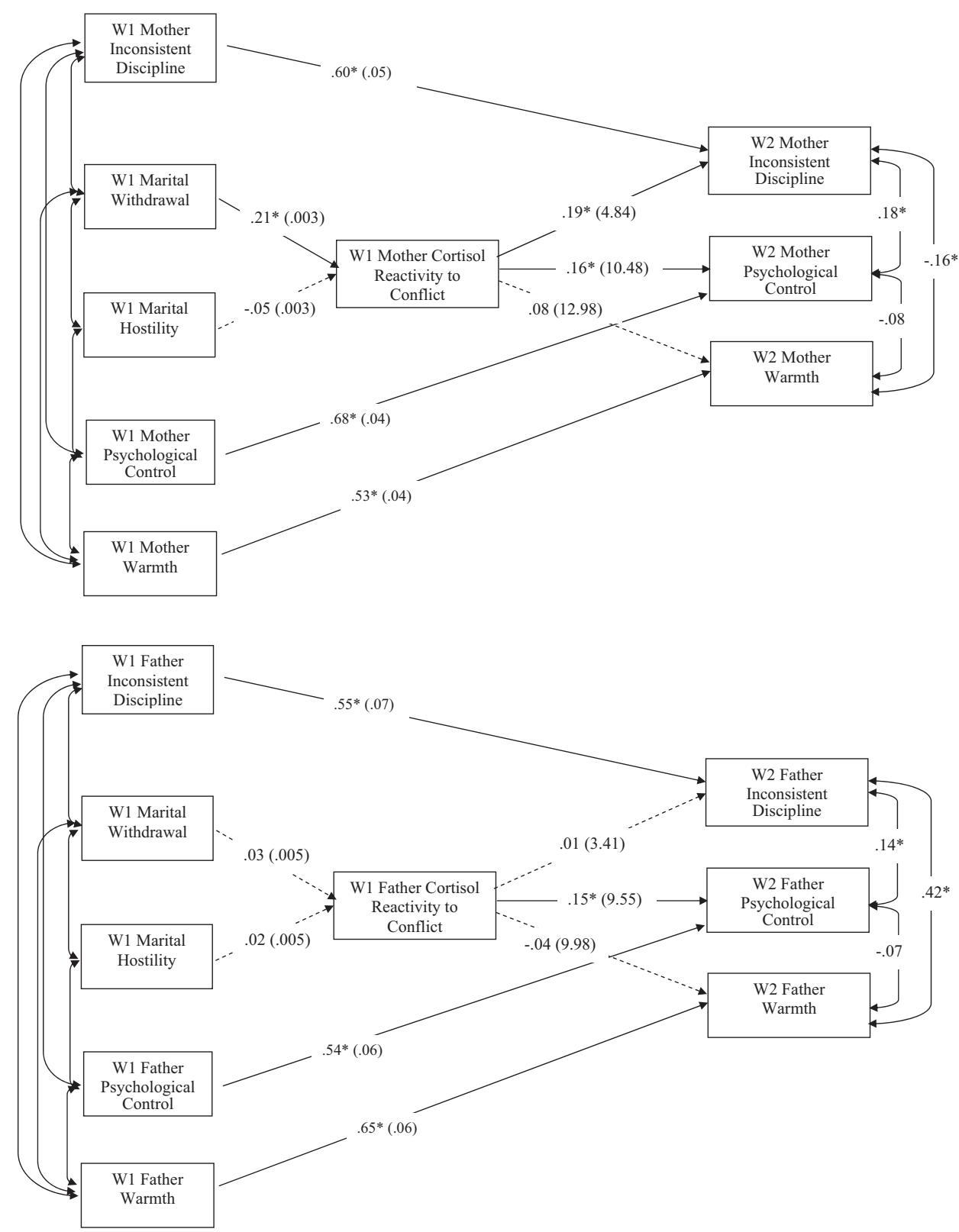

Figure 1. Process model outlining indirect pathways of the association between interparental hostility and withdrawal, parental cortisol reactivity to conflict, and parenting practices from Wave 1 to Wave 2 . * $p \leq .05$. 
cance $(\beta=.10, p>.05)$ with the inclusion of the cortisol reactivity path in the model, while the pathway predicting maternal psychological control was still significant $(\beta=$ $.14, p<.05)$ suggesting partial mediation.

Finally, to further illuminate the process of how mother's cortisol reactivity to interparental withdrawal may set in motion perturbations in subsequent parenting practices, we tested the significance of the indirect pathway from interparental withdrawal at Time 1 to mother's cortisol reactivity to increases in mother's use of psychological control and inconsistent discipline from Time 1 to Time 2 utilizing procedures for examining the statistical significance of indirect paths (Sobel, 1982). The indirect pathways $(\alpha \beta)$ for both inconsistent discipline and psychological control were significant, $z=2.29$ and $z=2.23$ respectively, $p<.05$. In substantive terms, these results support the mediating role of mother's cortisol reactivity in relationships between interparental withdrawal and parenting practices. Finally, while our interparental conflict variables were not predictive of fathers' cortisol reactivity during interparental disagreements, our analyses did reveal that reactivity was associated with fathers' use of greater psychological control of their children over time $(\beta=.15, p<.05)$. No other findings for fathers were significant.

\section{Discussion}

The results of this study supported the applicability of the hypercortisolism hypothesis to affective spillover models for relations between interparental conflict and parenting. In partial support of the hypercortisolism hypothesis, heightened cortisol reactivity in reaction to interparental withdrawal in mothers, served as a mediating mechanism in two of the three pathways between interparental withdrawal and maternal parenting practices over time. In particular, the role of amplified maternal adrenocortical reactivity as a mediating mechanism of interparental withdrawal was particularly robust in the prediction of subsequent increases in maternal inconsistent discipline and use of psychological control.

In understanding the transactional process whereby elevated cortisol in response to the stresses associated with interparental withdrawal may result in diminished parenting, it may be helpful to consider the impact of cortisol reactivity on related biological domains. As cortisol levels increase, neural processing regions in the brain that underlie the handling of emotional events, including the hippocampus and the amygdala, are adversely affected, which in turn may result in excessive perceptual bias toward perceiving negative stimuli and cognitive deficits including apathy, impaired concentration, and depression (Erikson, Drevets, $\&$ Schulkin, 2003). Thus, within this framework, the impact of amplified cortisol reactivity arising from interactions within the interparental relationship may undermine the attentional and cognitive requirements necessary for parents to effectively process children's behaviors and arrive at consistent and appropriate caregiving solutions as they may be prone to more negative interpretive biases as well as limited emotional resources to effectively administer parenting in difficult child-rearing situations. Earlier work within parenting domains lends partial support to this interpretation of the findings in the present study. For example, a study conducted by Martorell and Bugental (2007) reported that elevated cortisol during stressful mother-child interactions mediated the relationship between mother's perceptions of her child as being difficult and her increased use of harsh discipline with her child.

However, these general findings are qualified by the presence of intriguing gender differences which emerged in model analyses. More specifically, cortisol reactivity was a particularly powerful mediator between interparental withdrawal and parenting in mothers but not fathers. These findings support previous research detailing how interparental disengagement and withdrawal are associated with greater elevated cortisol reactivity in wives and not husbands. For example, Kiecolt-Glaser and colleagues (1996) reported that wives had greater cortisol responses to marital conflict than husbands. Elevated cortisol reactivity of wives was particularly pronounced in response to marital withdrawal during conflict. However, the present study expanded upon previous research by simultaneously considering two types of interparental conflict and found stronger associations between interparental withdrawal when compared with interparental hostility between husbands and wives.

Consistency in findings across studies begs the question of why interparental withdrawal is associated with greater adrenocortical reactivity. According to biopsychosocial models of adrenocortical reactivity to situations involving challenge and threat, the LHPA axis is most likely to be activated when stressful contexts exceed the resources and capacities of the individual (Blascovich \& Tomaka, 1996; Deinstbier, 1989). By the same token, conceptualizations of marital quality maintain that withdrawal is a more destructive process than anger expression because it reflects psychological abandonment and detachment of spouses and prevents the resolution of serious marital problems (Christensen \& Heavey, 1990; Gottman, 1993). Thus, one interpretation is that interparental withdrawal signifies a particularly potent threat to maintaining stability of the family system, resulting in the activation of the HPA axis which serves the adaptive function of marshalling resources and reducing or addressing the threat and preserving the stability of the family system.

Why might this process only operate for wives? Gender differences in personality may be one explanation. Women have been shown to exhibit greater sensitivity and investment in close interpersonal relationships than men (e.g., Thompson \& Walker, 1989). As one manifestation of this orientation, wives may have exhibit greater adrenocortical reactivity to withdrawal by virtue of their acute sensitivity to detecting and deciphering the implications of destructive relationship processes. Similarly, social role theory posits that wives may be more likely than husbands to assume the role of relational gatekeepers of the family and, in the process, place more value on their roles as spouse and 
parent. Thus, women may respond with greater cortisol reactivity to threats to the integrity of the family unit (Belsky, Youngblade, Rovine, \& Volling, 1991; Lindahl, Clements, \& Markman, 1997).

Fully interpreting the results of our study also requires consideration of the methodological limitations. First, while the present study employed multimethod assessments of constructs across the three domains (interparental, physiological, and parenting), the use of multi-informant assessments within domain would strengthen the validity of our assessments. Second, future research on family process models detailing mothers' and fathers' cortisol functioning in the context of interparental conflict would benefit by increasing the rigor of physiological assessments. For example, our demarcation of cortisol reactivity is based upon change between pre and post samples only. Although this method has been consistently used in the literature, repeated sampling would allow for a more precise measurement of the nature of the cortisol trajectory in response to and recovery from a stressor (e.g., Davies, Sturge-Apple, Cicchetti, \& Cummings, 2007; Laurent \& Powers, 2007). In addition, contextualizing the study of cortisol within broader profiles of functioning across multiple physiological systems may also advance psychophysiological models of coping with family conflict (Doussard-Roosevelt, Montgomery, \& Porges, 2003; Gordis, Granger, Susman, \& Trickett, 2006; Granger et al., 2006). For example, the modest to moderate magnitude of associations between psychological and physiological reactivity to conflict may be augmented by analyses of synchrony in functioning between the LHPA axis and the parasympathetic (e.g., Doussard-Roosevelt et al., 2003) or sympathetic (e.g., Gordis et al., 2006) nervous systems. Finally, although the demographic characteristics of our sample of families were highly comparable to the Northeast and Midwest regions of the United States, the findings in this study were derived from a community sample of predominantly White families. Therefore, the results of our study may not necessarily generalize to families with other racial, ethnic, or high-risk backgrounds.

In summary, the current study extends prior research on spillover between interparental conflict and parent-child subsystems by demonstrating that relations between these constructs may be mediated by parental physiological reactivity to conflict. To our knowledge, this was the first study to simultaneously delineate the mediational role of adrenocortical reactivity in longitudinal associations between marital hostility and withdrawal and three distinct parenting dimensions, warmth, psychological control and inconsistency in discipline. Differences in the effects of marital hostility and withdrawal on maternal and paternal parenting constructs as well as on the intermediary role of adrenocortical reactivity highlight the importance of incorporating a multi-levels of analysis perspective in investigating mechanisms of spillover between specific types of marital conflict and the parent-child subsystem (e.g., Cicchetti \& Dawson, 2002).

In this regard, assessments and interventions with distressed families may benefit from including a focus on the experiential and physiological components of negative emotion in both marital and parent-child subsystems during therapeutic intervention. For example, the differential impact of different approaches (e.g., cognitive reframing versus psychodynamic approaches) could include an assessment of their impact on subsequent cortisol reactivity during marital conflict. Cortisol reactivity is rarely employed as a potentially valuable outcome measure. Finally, the results of this study indicate that current heterogeneity in mediational models examining the deleterious effects of marital conflict on parenting may be attributable, in part, to the lack of multiple levels of analysis conceptualizations utilized in previous studies, and that advancement in understanding how marital conflict influences parenting depends upon incorporating constructs across different biopsychological domains in examinations of affective spillover in future studies.

\section{References}

Arbuckle, J. L., \& Wothke, W. (1999). Amos 4.0 User's Guide. Chicago: Smallwaters Corporation.

Baumrind, D. (1971). Current patterns of parental authority. Developmental Psychology Monograph, 4(1 pt 2), 1-103.

Beach, S. R., \& Fincham, F. D. (1998). Marital processes and depression. In: Luciano L'Abate (Ed.), Family psychopathology: The relational roots of dysfunctional behavior (pp. 256-279). New York: Guilford Press.

Belsky, J., Youngblade, L., Rovine, M., \& Volling, B. (1991). Patterns of marital change and parent-child interaction. Journal of Marriage and the Family, 53, 487-498.

Bentler, P. M. (1990). Comparative fit indexes in structural models. Psychological Bulletin, 107, 238-246.

Blascovich, J., \& Tomaka, J. (1996). The biopsychosocial model of arousal regulation. In M. P. Zanna (Ed.), Advances in experimental social psychology, Vol. 28 (pp. 1-51). New York: Academic Press.

Browne, M. W., \& Cudeck, R. (1993). Alternative ways of assessing model fit. In K. A. Bollen \& J. S. Long (Eds.), Testing structural equation models (pp. 136-162). Beverly Hills, CA: Sage Publications.

Burman, B., \& Margolin, G. (1992). Analysis of the association between marital relationships and health problems: An interactional perspective. Psychological Bulletin, 112, 39-63.

Cahill, L., \& McGaugh, J. L. (1998). Mechanisms of emotional arousal and lasting declarative memory. Trends in Neurosciences, 21, 294-299.

Christensen, A., \& Heavey, C. L. (1990). Gender and social structure in demand/withdraw pattern of marital conflict. Journal of Personality and Social Psychology, 59, 73-81.

Chrousos, G. P., \& Gold, P. W. (1992). The concepts of stress and stress system disorders: Overview of physical and behavioral homeostasis. Journal of the American Medical Association, 267, 1244-1252.

Cicchetti, D., \& Dawson, G. (Eds.) (2002). Multiple levels of analysis [Special Issue]. Development and Psychopathology, 14, 417-666.

Cummings, E. M., Davies, P., \& Campbell, S. B. (2000). Developmental psychopathology and family process: Theory, research, and clinical implications. New York: Guilford Press.

Davies, P. T., \& Cicchetti, D. (Eds.). (2004). Special Issue: Family systems and developmental psychopathology. Development and Psychopathology, 16, 477-481. 
Davies, P. T., \& Lindsay, L. (2001). Does gender moderate the effects of conflict on children? In J. H. Grych \& F. D., Fincham (Eds.), Child development and interparental conflict (pp. 64-97). New York: Cambridge University Press.

Davies, P. T., Sturge-Apple, M. L., Cicchetti, D., \& E. M. Cummings. (2007). The role of child adrenocortical functioning in pathways between interparental conflict and child maladjustment. Developmental Psychology, 43, 918-930.

Deinstbier, R. A. (1989). Arousal and physiological toughness: Implications for mental and physical health. Psychological Review, 96, 84-100.

Dickerson, S. S., \& Kemeny, M. E. (2004). Acute stressors and cortisol responses: A theoretical integration and synthesis of laboratory research. Psychological Bulletin, 130, 355-391.

Doussard-Roosevelt, J. A., Montgomery, L. A., \& Porges, S. W. (2003). Short-term stability of physiological measures in kindergarten children: Respiratory sinus arrhythmia, heart period, and cortisol. Developmental Psychobiology, 43, 231-242.

Du Rocher Schudlich, T. D., Papp, L. M., \& Cummings, E. M. (2004). Relations of husbands' and wives' dysphoria to marital conflict resolution strategies. Journal of Family Psychology, 18, 171-183.

Easterbrooks, M. A., \& Emde, R. N. (1988). Marital and parentchild relationships: The role of affect in the family system. In R. Hinde \& J. Stevenson-Hinde (Eds.), Relationships within families: Mutual influences (pp. 83-103). New York: Oxford University Press.

Emery, R. E., Fincham, F. D., \& Cummings, E. M. (1992). Parenting in context: Systemic thinking about parental conflict and its influence on children. Journal of Consulting and Clinical Psychology, 60, 909-912.

Erikson, K., Drevets, W., \& Schulkin, J. (2003). Glucocorticoid regulation of diverse cognitive functions in normal and pathological emotional states. Neuroscience and Biobehavioral Reviews, 27, 233-246.

Fox, N. A., Hane, A. A., \& Perez-Edgar, K. (2006). Psychophysiological methods for the study of developmental psychopathology. In D. Cicchetti \& D. J. Cohen (Eds.), Developmental psychopathology. Vol. 2: Developmental neuroscience (2nd ed., pp. 381-426). New York: Wiley \& Sons.

Gordis, E. B., Granger, D. A., Susman, E. J., \& Trickett, P. K. (2006). Asymmetry between salivary cortisol and alpha -amylase reactivity to stress: Relation to aggressive behavior in adolescents. Psychoneuroendocrinology, 31, 976-987.

Gottman, J. M. (1993). The roles of conflict engagement, escalation, and avoidance in marital interaction: A longitudinal view of five types of couples. Journal of Consulting \& Clinical Psychology, 61, 6-15.

Gottman, J. M., \& Levenson, R. W. (1988). The social psychophysiology of marriage. In P. Noller \& M. A. Fitzpatrick (Eds). Perspectives on marital interaction: Monographs in social psychology of language, No. 1 (pp. 182-200). Clevedon, England: Multilingual Matters Ltd.

Granger, D. A., Kivlighan, K. T., Blair, C., El-Sheikh, M., Mize, J., Lisonbee, J. A. (2006). Integrating the measurement of salivary alpha-amylase into studies of child health, development, and social relationships. Journal of Social and Personal Relationships, 23, 267-290.

Granger, D. A., Weisz, J. R., \& Kauneckis, D. (1994). Neuroendocrine reactivity, internalizing behavior problems, and controlrelated cognitions in clinic-referred children and adolescents. Journal of Abnormal Psychology, 103, 267-276.

Granger, D. A., Weisz, J. R., McCracken, J. T., Ikeda, S. C., \& Douglas, P. (1996). Reciprocal influences among adrenocortical activation, psychosocial processes, and the behavioral adjustment of clinic-referred children. Child Development, 67, 32503262 .

Grych, J. H. (2002). Marital relationships and parenting. In M. H. Bornstein (Ed.), Handbook of parenting (2nd ed., pp. 203-225). Mahwah, NJ: Lawrence Erlbaum Associates, Inc.

Gunnar, M. R., \& Vazquez, D. M. (2006). Stress neurobiology and developmental psychopathology. In D. Cicchetti \& D. J. Cohen (Eds.), Developmental Psychopathology. Vol. 2: Developmental Neuroscience (2nd ed., pp. 533-577). New York: Wiley \& Sons. Katz, L. F., \& Gottman, J. M. (1996). Spillover effects of marital conflict: In search of parenting and coparenting mechanisms. New Directions for Child Development, 74, 57-76.

Kiecolt-Glaser, J. K., Glaser, R., Cacioppo, J. T., \& Malarkey, W. B. (1998). Marital stress: Immunologic, neuroendocrine, and autonomic correlates. Annals of the New York Academy of Sciences, 840, 649-655.

Kiecolt-Glaser, J. K., \& Newton, T. (2001). Marriage and health: His and hers. Psychological Bulletin, 127, 472-503.

Kiecolt-Glaser, J. K., Newton, T., Cacioppo, J. T., MacCallum, R. C., Glaser, R., \& Malarkey, W. B. (1996). Marital conflict and endocrine function: Are men really more physiologically affected than women? Journal of Consulting and Clinical Psychology, 64, 324-332.

Kline, R. B. (2006). Principles and Practice of Structural Equation Modeling. New York: Guilford Press.

Laurent, H., \& Powers, S. (2007). Emotion regulation in emerging adult couples: Temperament, attachment, and HPA response to conflict. Biological Psychology, 76, 61-71.

Lindahl, K. M., Clements, M., \& Markman, H. (1997). Predicting marital and parent functioning in dyads and triads: A longitudinal investigation of marital processes. Journal of Family Psychology, 11, 139-151.

Locke, H. J., \& Wallace, K. M. (1959). Short marital adjustment prediction tests: Their reliability and validity. Marriage and Family Living, 21, 251-255.

Lopez, N. L., Vazquez, D. M., \& Olson, S. L. (2004). An integrative approach to the neurophysiological substrates of social withdrawal and aggression. Development and Psychopathology, 16, 69-93.

Lorber, M. G.,\& O'Leary, S. G. (2005). Predicting overreactive discipline: Mediated cognitive, affective, and psychophysiological processes. Journal of Consulting and Clinical Psychology, 73, 972-981.

Malik, N. M., \& Lindahl, K. M. (1996). System for coding interactions in dyads (SCID). Unpublished manual, University of Miami, Coral Gables, FL.

Margolies, P., \& Weintraub, S. (1977). The revised 56-item CRPBI as a research instrument: Reliability and factor structure. Journal of Clinical Child Psychology, 25, 262-271.

Martorell, G. A., \& Bugental, D. B. (2006). Maternal variations in stress reactivity: Implications for harsh parenting practices with very young children. Journal of Family Psychology, 20, 641647.

McEwen, B. S., \& Stellar, E. (1993). Stress and the individual: Mechanisms leading to disease. Annals of Internal Medicine, 153, 2093-2102.

National Survey of Children's Health. (2003). U.S. Dept. of Health and Human Services, Centers for Disease Control and Prevention, National Center for Health Statistics. [Computer file]. ICPSR04691-v1. Hyattsville, MD: U.S. Dept. of Health and Human Services, Centers for Disease Control and Prevention, National Center for Health Statistics [producer], 2005. Ann Ar- 
bor, MI: Inter-University Consortium for Political and Social Research [distributor], 2007-05-24. doi:10.3886/ICPSR04691

Owen, M. T., \& Cox, M. J. (1997). Marital conflict and the development of infant-parent attachment relationships. Journal of Family Psychology, 11, 152-164.

Repetti, R. L., Taylor, S. E., \& Seeman, T. S. (2002). Risky families: Family social environments and the mental and physical health of the offspring. Psychological Bulletin, 128, 330366.

Rohner, R. P. (1990). Handbook for the study of parental acceptance and rejection. Storrs, CT: University of Connecticut, Center for the Study of Parental Acceptance and Rejection.

Salimetrics, LLC. (2000). HS cortisol kit information. Unpublished manuscript, State College, PA.

Schludermann, E., \& Schludermann, S. (1970). Replicability of factors in children's report of parent behavior (CRPBI). Journal of Psychology, 76, 239-249.

Schwartz, E. P., Granger, D. A., Susman, E. J., Gunnar, M. R., \& Laird, B. (1998). Assessing salivary cortisol in studies of child development. Child Development, 69, 1503-1513.

Schwarz, J. C., Barton-Henry, M. L., \& Pruzinsky, T. (1985). Assessing child-rearing behaviors: A comparison of ratings made by mother, father, child, and sibling on the CRPBI. Child Development, 56, 462-479.

Shelton, K. K., Frick, P. J., \& Wootton, J. (1996). Assessment of parenting practices in families of elementary school-age children. Journal of Clinical Child Psychology, 25, 317-329.
Sobel, M. E. (1982). Asymptotic confidence intervals for indirect effects in structural equation models. In S. Leinhardt (Ed.), Sociological methodology 1982 (pp. 290-312). Washington, DC: American Sociological Association.

Stansbury, K., \& Gunnar, M. R. (1994). Adrenocortical activity and emotion regulation. In N. A. Fox (Ed.), The Development of Emotion Regulation: Biological and behavioral considerations. Monographs of the Society for Research in Child Development, 59, $108-134$

Steinberg, L., Elmen, J., \& Mounts, N. (1989). Authoritative parenting, psychosocial maturity, and academic success among adolescents. Child Development, 60, 1424-1436.

Sturge-Apple, M., L., Davies, P. T., \& Cummings, E. M. (2006). The impact of interparental hostility and withdrawal on parental emotional unavailability and children's adjustment difficulties. Child Development, 77, 1623-1641.

Sturge-Apple, M. L., Davies, P. T., Boker, S. M., \& Cummings, E. M. (2004). Interparental discord and parenting: Testing the moderating role of child and parent gender. Parenting: Science and Practice, 4, 365-384.

Thompson, E., \& Walker, A. (1989). Gender in families: Women and men in marriage, work, and parenthood. Journal of Marriage and the Family, 51, 845-872.

Received April 22, 2008

Revision received August 21, 2008 Accepted September 14, 2008

\section{E-Mail Notification of Your Latest Issue Online!}

Would you like to know when the next issue of your favorite APA journal will be available online? This service is now available to you. Sign up at http://notify.apa.org/ and you will be notified by e-mail when issues of interest to you become available! 